\title{
SEROPREVALENCE OF CHAGAS DISEASE IN DWELLERS OF THE XI REGIONAL HEALTH ADMINISTRATION DISTRICTS, SÃO PAULO STATE, BRAZIL
}

THESIS. I. Godoy submitted this thesis for her Doctorate in Tropical Diseases at Botucatu School of Medicine, São Paulo State University, UNESP, Botucatu, São Paulo, Brazil, 2003.

Advisor: Professor Domingos Alves Meira

ABSTRACT: Chagas disease has been considered one of the most important public health problems among the diseases transmitted by vectors. The most effective way to avoid its manifestation is by controlling congenital, vectorial and blood transfusion transmission. Less common forms of transmission, such as solid organs, blood marrow, and tissue transplantation also need to be verified. Control measures against Triatoma infestans have been considered successful in the state of São Paulo; however, epidemiological surveillance and adequate financial support are fundamental to verify and maintain this state-of-the-art condition. The aim of this study was to look for evidences of the Chagas disease vectorial transmission, after 1983, in dwellings and neighboring areas within the XI Regional Health Administration Districts, where xenodiagnosis-positive patients lived. In that year, vectorial control was obtained and the distribution of residential vectors was wellknown in the state. To reach this objective, two groups of study were elected: the first one contained individuals born before 1983, and the second, individuals born after this year. The population was selected based on the addresses of xenodiagnosispositive patients, who were followed up at the outpatient clinic of the Department of Tropical Diseases, Botucatu School of Medicine, UNESP. Fifty-eight individuals were selected and had blood samples collected for laboratory analysis. Indirect hemagglutination (IHA), indirect immunofluorescence (IIF), and enzyme-linked immunosorbent assay (ELISA) were used to identify anti-T.cruzi antibodies. Trypanosoma cruzi isolated was obtained by hemoculture in liver infusion tryptose 
(LIT) medium, polymerase chain reaction (PCR), and artificial xenodiagnosis. Individuals from both groups presented low formal education level, had been working on unskilled professions, and were predominantly represented by females. At the moment of the study, there was a slight improvement in the individuals' dwelling conditions and an increase in the number of dwellers in rural areas, compared to previous conditions. Chagas disease was present, as a previous disease, in mothers from both groups. Individuals born before 1983, showed significant higher knowledge of and/or contact with triatomine. The majority of the individuals had not received blood transfusion. Analyzing and comparing the results of serological tests, including IHA, IIF, and ELISA, the latter showed better sensitivity. The results of this study revealed that the population born after 1983 did not know the physical characteristics of the Chagas disease vector. Taking into consideration the importance of triatomine notification by the population and the surveillance method prioritized since 1983, the efficacy of disease control may be affected. It is evident the importance of searching for alternative tolls that favor a high involvement of the population in the triatomine surveillance. Based on this study, it is not possible to state that triatomine was eliminated, even considering that we did not identify vectors in the patients' dwellings or in their neighboring areas. Therefore, further entomological and serological investigations are necessary to maintain a regular evaluation of the Chagas disease control program efficacy in the state of São Paulo.

KEY WORDS: Chagas disease, Triatoma infestans, vectorial transmission, xenodiagnosis.

\section{CORRESPONDENCE TO:}

I. GODOY, Departamento de Doenças Tropicais e Diagnóstico por Imagem, Faculdade de Medicina de Botucatu, UNESP, Distrito de Rubião Junior, s/n, 18618000, Botucatu, SP, Brasil. Phone: 55143811 6212. Email: d.meira@uol.com.br 